\title{
Fluid resuscitation in critically ill patients: a systematic review and network meta-analysis
}

This article was published in the following Dove Press journal:

Therapeutics and Clinical Risk Management

\author{
Chao Liu'** \\ Zhi Mao',* \\ Pan $\mathrm{Hu}^{1}, *$ \\ Xin $\mathrm{Hu}^{\prime}$ \\ Hongjun Kang' \\ Jie $\mathrm{Hu}^{\prime}$ \\ Zhifang Yang ${ }^{2}$ \\ Penglin $\mathrm{Ma}^{3}$ \\ Feihu Zhou ${ }^{1,4}$ \\ 'Department of Critical Care \\ Medicine, Chinese People's Liberation \\ Army General Hospital, Beijing, \\ People's Republic of China; ${ }^{2}$ Beijing \\ Institute of Pharmacology and \\ Toxicology, Beijing, People's Republic \\ of China; ${ }^{3}$ Department of Critical \\ Care Medicine, the 309th Hospital \\ of Chinese People's Liberation Army, \\ Beijing, People's Republic of China; \\ ${ }^{4}$ National Clinical Research Center \\ for Kidney Diseases, Chinese People's \\ Liberation Army General Hospital, \\ Beijing, People's Republic of China \\ *These authors contributed equally \\ to this work
}

Correspondence: Feihu Zhou Department of Critical Care Medicine, Chinese People's Liberation Army General Hospital, 28 Fu-Xing Road, Beijing 100853, People's Republic of China

Tel +86 I06 6938148

Fax +86 I08 82I 9862

Email feihuzhou30I@I26.com

Penglin Ma

Department of Critical Care Medicine, the 309th Hospital of Chinese People's Liberation Army, Beijing 10009I, People's Republic of China

Tel +86 I38 I0339898

Email mapenglin I@I63.com
Objective: The aim of this study was to compare the effectiveness of different fluids on critically ill patients who need fluid resuscitation through a systematic review and network meta-analysis (NMA).

Data sources: Electronic databases were searched up to March 2018 for randomized controlled trials comparing the effectiveness of different fluids in critically ill patients. The primary outcome was mortality, and the secondary outcomes were the incident of acute kidney injury (AKI) and risk of receiving renal replacement therapy (RRT). A Bayesian NMA was conducted, and the quality of evidence contributing to each network estimate was assessed using the Grading of Recommendations Assessment, Development and Evaluation (GRADE) Working Group criteria.

Results: We deemed 49 trials eligible, including 40,910 participants. The quality of evidence was rated as moderate in most comparisons. There was no significant difference among resuscitation fluids in mortality. NMA at the 9-node level showed the most effective fluid was balanced crystalloid (BC) $(80.79 \%$, the ranking of resuscitation fluid based on cumulative probability plots and surface under the cumulative ranking curves [SUCRAs]). NMA at the 10-node level showed that the most effective fluid was Plasma-Lyte (77.52\%). Results of sensitivity analyses in mortality did not reveal any significant changes in the findings for primary outcomes. Highmolecular-weight hetastarch (H-HES) was associated with an increased incidence of AKI when compared with gelatin (odds ratio [OR], 0.43; 95\% credibility interval [CrI], 0.19-0.94), lowmolecular-weight hetastarch (L-HES; OR, 0.50; 95\% CrI, 0.30-0.87), BC (OR, 0.55; 95\% CrI, 0.34-0.88), and normal saline (OR, 0.56; 95\% CrI, 0.34-0.93). Meanwhile, H-HES was also associated with an increased risk of receiving RRT when compared with $\mathrm{BC}(\mathrm{OR}, 0.51 ; 95 \% \mathrm{CrI}$, 0.27-0.93) and normal saline (OR, 0.52; 95\% CrI, 0.24-0.96).

Conclusion: BCs, especially the Plasma-Lyte, are presumably the best choice for most critically ill patients who need fluid resuscitation. Meanwhile, the use of H-HES was associated with an increased incidence of AKI and risk of receiving RRT.

Registration: PROSPERO (CRD42017072728).

Keywords: fluid resuscitation, critically ill, crystalloids, colloids, systematic review, network meta-analysis

\section{Introduction}

Fluids are a core element in the resuscitation of critically ill patients, and fluid management strategies vary widely in practice. Whether specific properties of these fluids may translate into a survival advantage remains unclear. ${ }^{1}$ Conflicting results from clinical trials and systematic reviews have not resolved this issue. The differing results may be due to a combination of factors including different patient populations, types and volumes of fluids, and the safety profile of the comparator fluids. ${ }^{2}$ 
Clinical studies have shown that colloids and crystalloids have different effects on a range of important physiological parameters. ${ }^{3}$ The most commonly used crystalloid, normal saline $(0.9 \%$ sodium chloride, with a $\mathrm{pH}$ much less than 7.0 , and a supraphysiologic chloride content of $154 \mathrm{mmol} / \mathrm{L}$ ), is thought to be more prone to cause hyperchloremic metabolic acidosis or may directly impact organ function and even survival when compared with other balanced crystalloid (BC) solutions (such as lactated Ringer's solution, Hartmann solution, acetate solutions, or Plasma-Lyte).4,5 Meanwhile, colloid solutions are thought to be more efficient than crystalloids to achieve equivalent hemodynamic effect. ${ }^{6}$ However, there are other effects of these fluids, including alterations of the immune response to critical illness. ${ }^{7}$ In addition, there is a concern that hetastarch may increase the risk of death or acute kidney injury (AKI).,3

Previous pairwise meta-analyses were conducted to evaluate the efficacy of all types of fluids and to identify factors associated with survival benefit. ${ }^{2,3,8}$ However, they either did not conduct direct and indirect comparisons in the same model or did not include data from recent large randomized control trials (RCTs). ${ }^{9-12}$ Therefore, we did a network meta-analysis (NMA) consisting of direct and indirect comparisons of all types of fluid resuscitation that were investigated in RCTs for critically ill patients to compare their effects on mortality, the incidence of AKI, and the need for renal replacement therapy (RRT).

\section{Materials and methods}

We adhered to the PRISMA Extension statement for reporting network meta-analyses (Table S1). ${ }^{13}$

\section{Data sources and search strategy}

We searched for literature in the MEDLINE, Embase, and the Cochrane Library databases from database inception to March 2018 for relevant citations of published trials using individualized search strategies prepared for each database. We also screened previously published meta-analyses for relevant citations. We contacted the authors for further study details when needed and searched the reference lists from primary and review articles. Table S2 presents the search terms used.

Six reviewers working in three pairs screened the titles and abstracts to determine the potential eligibility, and entries identified by any reviewer would proceed to the full text eligibility review. Any disagreements were resolved through consensus with the help of a third adjudicator.

\section{Selection criteria}

Types of studies

We included parallel-group RCTs only and excluded observational studies, quasi-randomized trials, and crossover trials. We also excluded two studies due to the lack of integrity. ${ }^{14,15}$

\section{Population}

Critically ill patients (age, $\geq 18$ years excluding pregnant women) as a result of trauma, burns, or other critical conditions such as complications of sepsis that required acute volume resuscitation were included. Preoperative elective surgical patients were excluded.

\section{Intervention}

We included studies which compared different fluid or fluid strategy used for resuscitation. We excluded studies in which fluids were used for maintenance rather than for resuscitation or those that used whole blood or blood products as comparators.

\section{Outcomes}

The primary outcome is mortality. Secondary outcomes are incidence of patients with renal injury defined according to the RIFLE (Risk, Injury, Failure, Loss of kidney function, and End-stage kidney disease) classification, glomerular filtration rate (GFR), and urine output and the need for RRT.

\section{Data extraction}

Raw data were extracted using a standardized, premade form. Data included the study design, year of publication, total number of patients, patient characteristics, and details regarding the outcomes. Six reviewers were divided into three groups with two reviewers in each group. Data were extracted in duplication. Any disagreements were solved through consensus in discussion with a third reviewer. The main endpoint was 28-day mortality. If mortality was assessed at several time points or only at an undetermined time point in a study, we used data from the latest follow-up time or the only undetermined time point.

\section{Risk of bias and quality of evidence assessment}

Risk of bias was assessed independently according to the Cochrane Collaboration's Risk of Bias tool. ${ }^{16}$ This tool consists of six standard criteria: random sequence generation, allocation concealment, blinding of participants and personnel, blinding of outcome assessment, incomplete outcome data, and selective reporting and other bias. ${ }^{17}$ In addition, 
we assessed the quality of evidence contributing to each network estimate according to the Grading of Recommendations Assessment, Development and Evaluation (GRADE) Working Group criteria, which characterizes the quality of a body of evidence on the basis of the study limitations, imprecision, inconsistency, indirectness, and publication bias for the primary outcomes. ${ }^{18}$ This approach classifies the strength of evidence as high, moderate, low, or very low.

\section{Data synthesis and statistical analyses}

Our analysis classified fluids as crystalloids (including BC, normal saline, and hypertonic saline [HS]) and colloids (including 4\% albumin, 20\% albumin, gelatin, dextran, low-molecular-weight hetastarch [L-HES], and highmolecular-weight hetastarch [H-HES; threshold molecular weight, 150,000 kDa]). Fluid was considered balanced if it contained an anion of a weak acid (buffer) and its chloride concentration was less than that in normal saline. ${ }^{19}$ In this study, the BC contains lactated Ringer's solution, PlasmaLyte A, Plasma-Lyte 148, and bicarbonate. Saline was considered hypertonic if its chloride content was more than that in normal saline. The relevant analysis was a 9-node NMA (BCs vs normal saline vs HS vs $4 \%$ albumin vs $20 \%$ albumin vs L-HES vs H-HES vs gelatin vs dextran) and a 10-node NMA (lactated Ringer's solution vs Plasma-Lyte [Plasma-Lyte A and Plasma-Lyte 148] vs normal saline vs HS vs $4 \%$ albumin vs $20 \%$ albumin vs L-HES vs H-HES vs gelatin vs dextran).

All analyses were performed using WinBUGs Bayesian software package and NetMetaXL (Cornerstone Research Group, Burlington, ON, Canada). ${ }^{20}$ We summarized the results of NMA with effect sizes (mean difference [MD] or odds ratio $[\mathrm{OR}]$ ) and their credibility intervals (CrIs). Heterogeneity across studies was quantified using the $I^{2}$ statistic, and $I^{2}>50 \%$ indicated significant heterogeneity. ${ }^{21}$ A Bayesian NMA was performed using a random effects model as it is the most conservative method to account for between-trial heterogeneity. ${ }^{22}$ Sensitivity analysis was performed to test the robustness of results. Subgroup analysis was conducted to investigate potential between-study heterogeneities. A $P$-value less than 0.05 was considered to indicate a statistically significant difference. Inconsistency between direct and indirect sources of evidence was statistically assessed by NetMetaXL. To provide a comparative hierarchy of fluid efficacy and safety, "rankograms" with surface under the cumulative ranking curve (SUCRA) probabilities were reported; A SUCRA of $90 \%$ means that the treatment of interest achieves $90 \%$ of effectiveness or safety relative to other interventions, and an intervention with a SUCRA value of 100 is considered to be the best, whereas an intervention with 0 is considered the worst. ${ }^{23}$ The funnel plot and Egger's test conducted by STATA software (version 13.0, StataCorp LP, College Station, TX, USA) were used to detect publication bias.

\section{Results \\ Study selection}

In total, 3,010 citations were identified by the search, and 1,785 potentially eligible full text articles were retrieved. One thousand six hundred and sixty-one studies were excluded after reviewing the titles and abstracts, and 124 full text articles left were reviewed carefully. Finally, $49 \mathrm{RCTs}^{9-12,24-68}$ were included in this systematic review and NMA as shown in Figure 1.

\section{Study characteristics}

Table S3 shows the characteristics of the included randomized trials. Thirty-three single-center ${ }^{11,12,24-34,36-40,42-44,}$

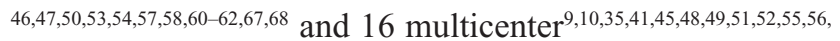
59,63-66 studies were identified. These trials were reported between 1977 and 2018, and a total of 40,910 patients were enrolled in the 49 studies. The mean age of the study participants ranged between 27 and 77 years, and the proportion of men ranged from $39 \%$ to $84 \%$. Two trials used mixture BC. ${ }^{11,12}$ The details of the risk of bias are shown in Figure S1. The quality of direct comparisons is shown in Table S4.

\section{Primary outcomes}

Figure 2 shows the 9-node NMA of eligible comparisons for mortality, and the results are presented as a league table in Figure 3. The 9-node NMA results showed that there was no significant difference among resuscitation fluids in the mortality of critically ill patients. The ranking of resuscitation fluid based on the cumulative probability plots and SUCRAs is presented in Figure 4. The most effective fluid was BC (80.79\%), and the second effective was HS (78.13\%; BC vs HS: OR, 1.03; 95\% CrI, 0.78-1.36). The 9-node NMA characteristics of primary outcomes are shown in Table S4. The heterogeneity was 0.08 (95\% CrI, 0.00-0.24) for mortality (Figure S2). The test of global inconsistency showed that there was no significant difference between the consistency and the inconsistency models for mortality (Figure S3). When we performed the 10-node NMA, two trials were excluded as they used mixture BC. ${ }^{11,12}$ Figure S4 shows the 10-node NMA of eligible comparisons for mortality, and the results are presented in Figure S5. The ranking of resuscitation fluid 


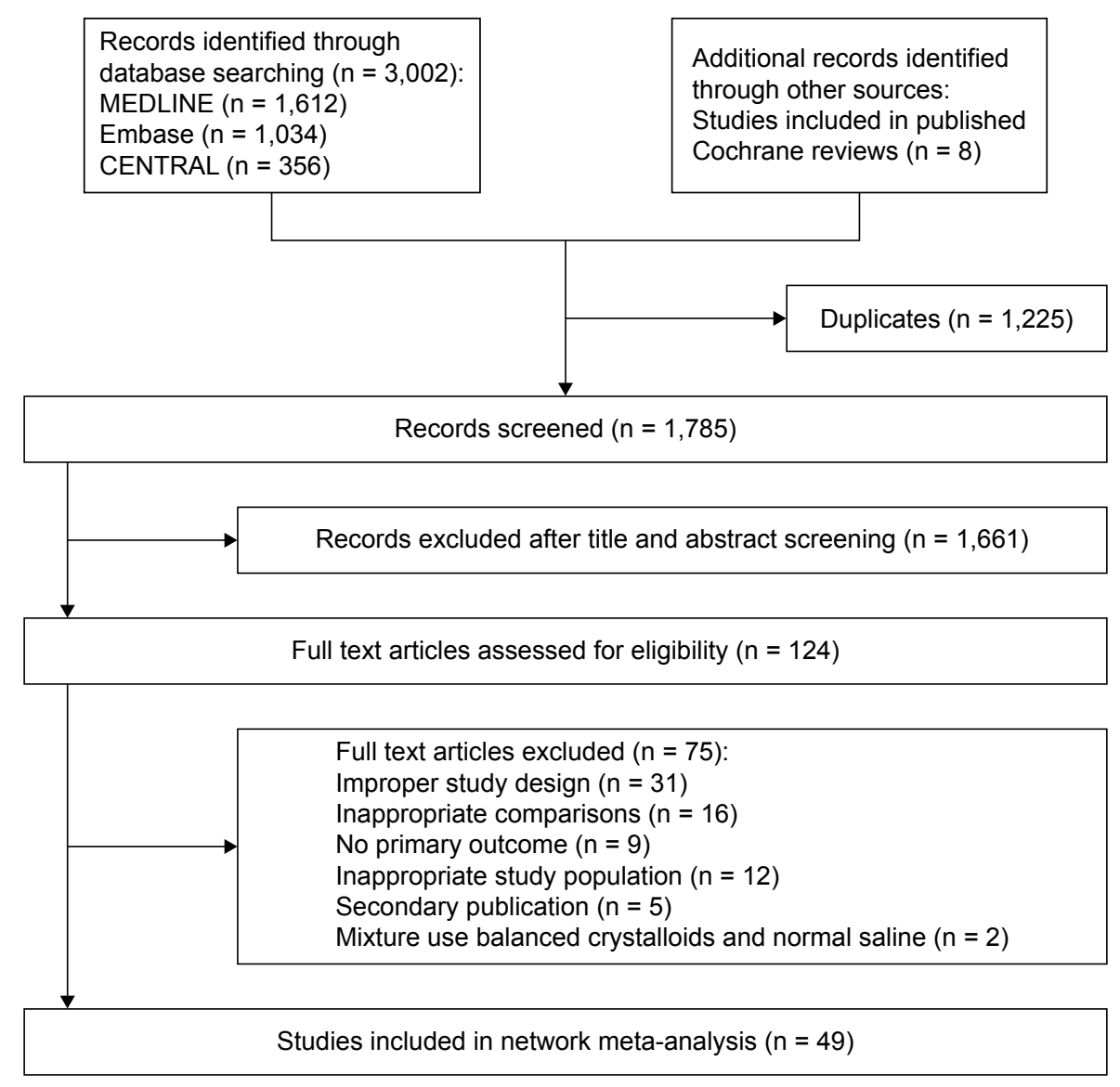

Figure I Study selection.

based on the cumulative probability plots and SUCRAs is presented in Figure S6. The most effective fluid was PlasmaLyte $(77.52 \%)$. Sensitivity analyses or subgroup analyses were performed to evaluate the influence of sample size

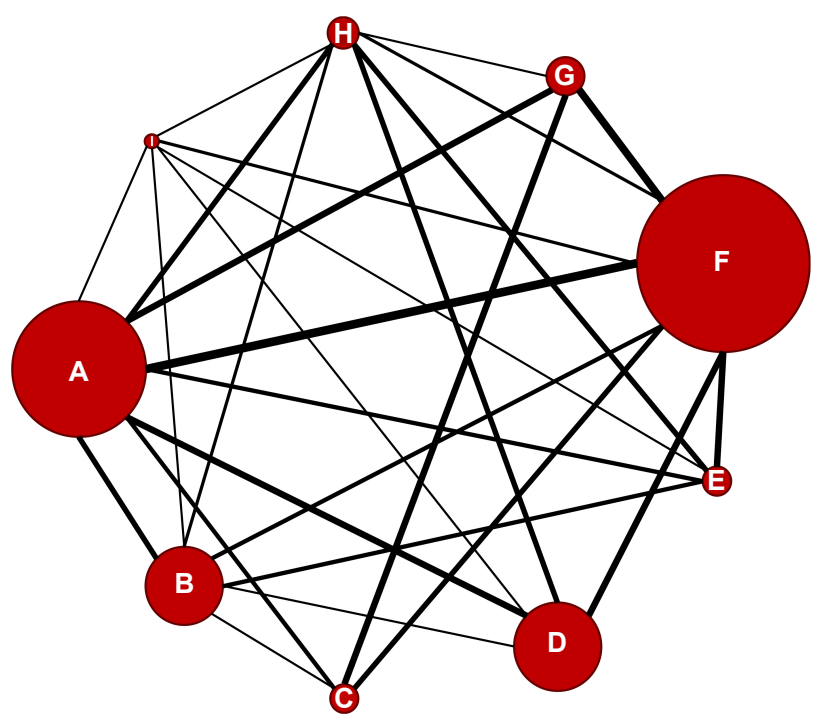

Figure 2 Network of eligible comparisons for mortality.

Notes: (A) Balanced crystalloid; (B) 4\% albumin; (C) hypertonic saline; (D) lowmolecular-weight hetastarch; (E) high-molecular-weight hetastarch; (F) $0.9 \%$ sodium chloride; (G) dextran; (H) gelatin; (I) $20 \%$ albumin. (participants more than 100), date of trial publication (after Surviving Sepsis Campaign [SSC] Guidelines), different diseases (sepsis, trauma, and hypovolemia), and age (mean age, $\geq 65$ years). Results of sensitivity analyses in mortality did not reveal any significant changes in the findings for primary outcomes. When studies with small sample size were excluded, the results showed that there was no significant difference among resuscitation fluids in reducing mortality (Figure S7). The network characteristics of large sample size studies were shown in Table S5. The most effective fluid was BC (75.77\%), and the second most effective was HS (73.82\%; BC vs HS: OR, 1.03; 95\% CrI, 0.73-1.49; Figure S8). When specifically investigating studies that were published after SSC guidelines, results showed that BC was more effective than H-HES in reducing mortality (OR, 0.65 ; 95\% CrI, 0.44-0.91; Figure S9). The network characteristics of the study published after SSC guidelines are shown in Table S6. The most effective fluid was BC (73.41\%), and the second most effective was dextran $(72.41 \%$; BC vs dextran: OR, 1.03; 95\% CrI, 0.65-1.53; Figure S10). Fifteen studies were included in sepsis subgroup. However, to reduce the heterogeneity, two studies with small sample size were excluded. The results showed that there was no significant difference 


\begin{tabular}{|c|c|c|c|c|c|c|c|c|}
\hline BC & & & & & & & & \\
\hline $\begin{array}{c}1.03 \\
(0.78-1.36)\end{array}$ & HS & & & & & & & \\
\hline $\begin{array}{c}1.00 \\
(0.79-1.24)\end{array}$ & $\begin{array}{c}0.97 \\
(0.73-1.28)\end{array}$ & DEX & & & & & & \\
\hline $\begin{array}{c}0.92 \\
(0.73-1.16)\end{array}$ & $\begin{array}{c}0.89 \\
(0.63-1.26)\end{array}$ & $\begin{array}{c}0.92 \\
(0.68-1.25)\end{array}$ & GEL & & & & & \\
\hline $\begin{array}{c}0.91 \\
(0.80-1.05)\end{array}$ & $\begin{array}{c}0.89 \\
(0.67-1.18)\end{array}$ & $\begin{array}{c}0.92 \\
(0.72-1.18)\end{array}$ & $\begin{array}{c}1.00 \\
(0.78-1.28)\end{array}$ & $4 \%$ ALB & & & & \\
\hline $\begin{array}{c}0.91 \\
(0.83-0.99)\end{array}$ & $\begin{array}{c}0.88 \\
(0.67-1.15)\end{array}$ & $\begin{array}{c}0.91 \\
(0.73-1.13)\end{array}$ & $\begin{array}{c}0.99 \\
(0.79-1.24)\end{array}$ & $\begin{array}{c}0.99 \\
(0.88-1.11)\end{array}$ & NS & & & \\
\hline $\begin{array}{c}0.88 \\
(0.78-0.99)\end{array}$ & $\begin{array}{c}0.86 \\
(0.65-1.13)\end{array}$ & $\begin{array}{c}0.89 \\
(0.70-1.12)\end{array}$ & $\begin{array}{c}0.96 \\
(0.76-1.21)\end{array}$ & $\begin{array}{c}0.96 \\
(0.83-1.12)\end{array}$ & $\begin{array}{c}0.97 \\
(0.88-1.07)\end{array}$ & L-HES & & \\
\hline $\begin{array}{c}0.73 \\
(0.48-1.12)\end{array}$ & $\begin{array}{c}0.71 \\
(0.43-1.16)\end{array}$ & $\begin{array}{c}0.73 \\
(0.46-1.17)\end{array}$ & $\begin{array}{c}0.79 \\
(0.50-1.26)\end{array}$ & $\begin{array}{c}0.80 \\
(0.52-1.23)\end{array}$ & $\begin{array}{c}0.80 \\
(0.53-1.23)\end{array}$ & $\begin{array}{c}0.83 \\
(0.54-1.27)\end{array}$ & $20 \%$ ALB & \\
\hline $\begin{array}{c}0.76 \\
(0.58-0.99)\end{array}$ & $\begin{array}{c}0.74 \\
(0.50-1.07)\end{array}$ & $\begin{array}{c}0.76 \\
(0.54-1.07)\end{array}$ & $\begin{array}{c}0.82 \\
(0.60-1.13)\end{array}$ & $\begin{array}{c}0.83 \\
(0.62-1.11)\end{array}$ & $\begin{array}{c}0.84 \\
(0.64-1.09)\end{array}$ & $\begin{array}{c}0.86 \\
(0.65-1.14)\end{array}$ & $\begin{array}{c}1.04 \\
(0.64-1.68)\end{array}$ & H-HES \\
\hline
\end{tabular}

Figure 3 Network meta-analysis of mortality.

Note: Data presented as OR ( $95 \% \mathrm{Crl})$.

Abbreviations: ALB, albumin; BC, balanced crystalloid; Crl, credibility interval; DEX, dextran; GEL, gelatin; H-HES, high-molecular-weight hetastarch; HS, hypertonic saline; L-HES, low-molecular-weight hetastarch; NS, $0.9 \%$ sodium chloride.

among resuscitation fluids in reducing mortality (Figure S11). The network characteristics of sepsis subgroup are shown in Table S7. The most effective fluid was 4\% albumin (73.52\%), the second most effective was BC (71.93\%), and the third most effective was normal saline $(71.88 \% ; 4 \%$ albumin vs BC: OR, 0.97; 95\% CrI, 0.41-2.35; Figure S12). In trauma subgroup, three studies were also excluded for small sample size. The results did not indicate any significant difference among resuscitation fluids in reducing mortality (Figure S13). The network characteristics of trauma subgroup are shown in Table S8. The most effective fluid was HS (78.11\%), followed by BC (69.27\%; HS vs BC: OR, 0.89; 95\% CrI, 0.38-2.08; Figure S14). No significant difference among resuscitation fluids was found in reducing mortality in the hypovolemia subgroup (Figure S15). The network characteristics of hypovolemia subgroup are shown in Table S9. The most effective fluid was dextran (72.16\%), followed by H-HES (65.16\%) (dextran vs H-HES: OR, 1.06; 95\% CrI, 0.23-5.45; Figure S16). Subgroup analysis on elderly patients (mean age, $\geq 65$ years) also showed no significant

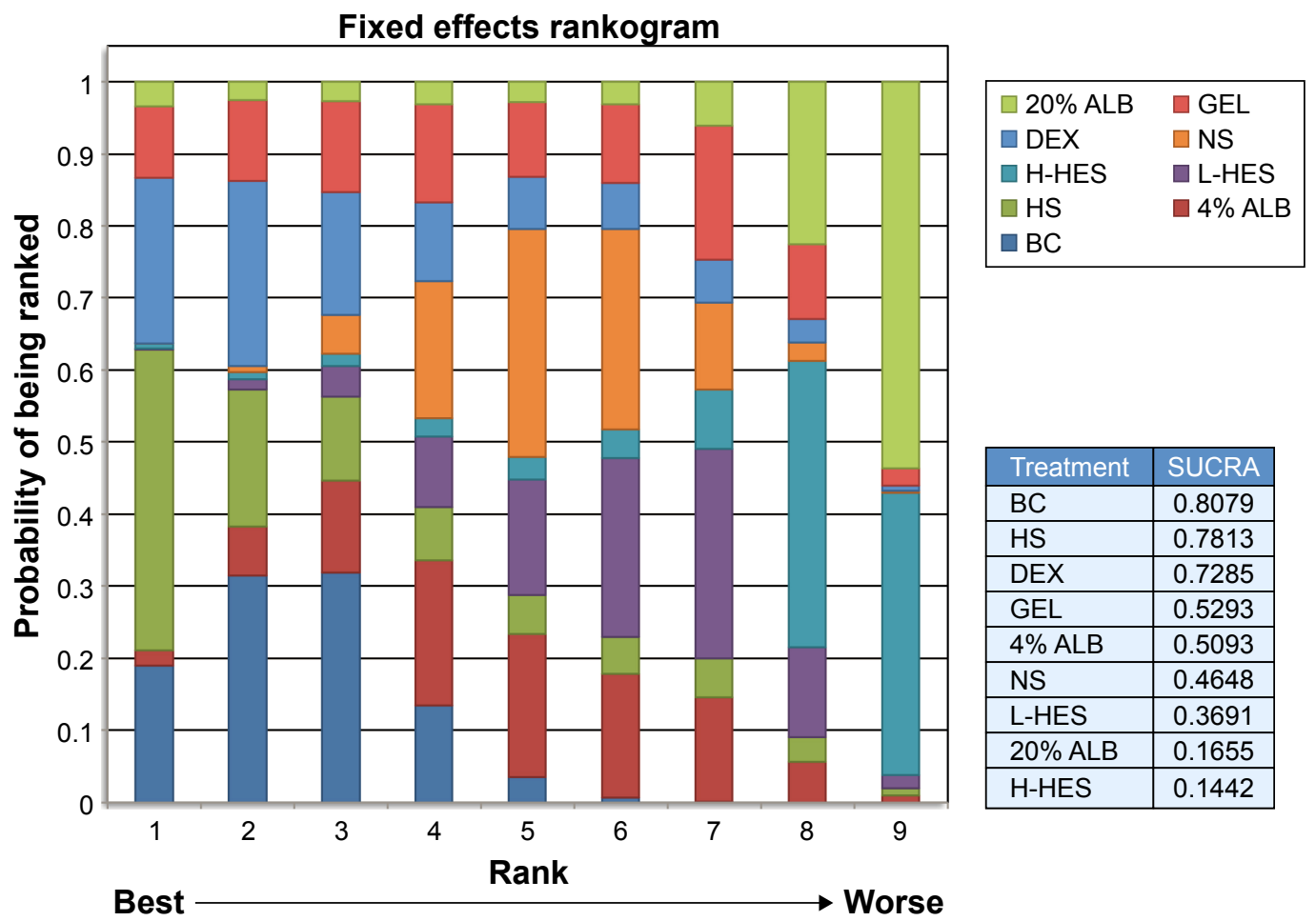

Figure 4 The ranking of resuscitation fluid based on the cumulative probability plots and SUCRAs.

Abbreviations: ALB, albumin; BC, balanced crystalloid; DEX, dextran; GEL, gelatin; H-HES, high-molecular-weight hetastarch; HS, hypertonic saline; L-HES, low-molecularweight hetastarch; NS, $0.9 \%$ sodium chloride; SUCRA, surface under the cumulative ranking curve. 
difference among resuscitation fluids in terms of decreasing mortality (Figure S17). The network characteristics of elderly patients subgroup is shown in Table S10. The most effective fluid was HS (69.28\%), followed by normal saline (60.78\%) and BC (58.69\%; HS vs normal saline: OR, 0.73; 95\% CrI, 0.06-8.70; Figure S18). The association between different regions or countries and the results was also analyzed, and no significant difference was found (data not shown).

\section{Secondary outcomes}

Thirteen studies reported the incidence of AKI. Results showed that H-HES was associated with an increased incidence of AKI when compared with gelatin (OR, 0.43; 95\% CrI, 0.19-0.94), L-HES (OR, 0.50; 95\% CrI, 0.30-0.87), BC (OR, 95\% CrI, 0.55; 0.34-0.88), and normal saline (OR, 0.56; 95\% CrI, 0.34-0.93). The results are presented in Figure S19. The network characteristics of studies reporting the incidence of AKI are shown in Table S11. Meanwhile, 13 studies reported the use of RRT. Pooled results showed an increased risk of receiving RRT in patients receiving $\mathrm{H}-\mathrm{HES}$ when compared with BC (OR, 0.51; 95\% CrI, 0.27-0.93; Figure S20) and normal saline (OR, 0.52; 95\% CrI, 0.24-0.96; Figure S20). The network characteristics of studies reporting the use of RRT are shown in Table S12. No significant evidence of publication bias for secondary outcomes was detected, and the strength of evidence was graded as moderate.

\section{Discussion}

This systematic review and NMA, incorporating direct and indirect evidence, provides a current and comprehensive summary of the effect of resuscitation fluids on mortality in critically ill patients. No significant difference was found among all included fluids in reducing mortality, and SUCRAs results indicated that $\mathrm{BC}$, especially the Plasma-Lyte, may be the most effective solution in terms of mortality benefit. The subgroup and sensitivity analyses also supported the results of primary outcomes. Secondary outcomes showed that the use of H-HES was associated with an increased incidence of AKI and risk of receiving RRT.

To provide more reliable results, we excluded two studies due to the lack of integrity. ${ }^{14,15}$ Furthermore, subgroup and sensitivity analyses were performed to evaluate the influence of sample size (less or more than 100 participants), date of trial publication (before or after SSC guidelines), different diseases (sepsis, trauma, and hypovolemia), and age (mean age, $\geq 65$ years) on primary and secondary outcomes. Subgroup analysis on studies published after the establish- ment of SSC guidelines showed that BC was more effective than $\mathrm{H}-\mathrm{HES}$ in reducing mortality (OR, 0.65; 95\% CrI, 0.44-0.91). The choice of fluids is often different for different diseases. In the subgroup analysis of septic patients, $4 \%$ albumin, BC, and normal saline have very similar SUCRAs results. Therefore, $4 \%$ albumin and $\mathrm{BC}$ may be reasonable alternatives to other resuscitation fluids for septic patients. In subgroup analysis of hypovolemic patients, colloids are significantly more effective for fluid resuscitation, as they may produce a larger increase in stroke volume than crystalloids. ${ }^{69}$ Thus, normal volume can be reached faster with colloids than with crystalloids. In subgroup analysis on elderly patients, the mortality was similar among different types of resuscitation fluids. Although SUCRAs results indicated that HS was the most superior for elderly patients, the strength of evidence was downgraded because of the risk of bias and indirectness.

Many meta-analyses on this topic have been published recently. One meta-analysis ${ }^{1}$ that examined the effect of different resuscitative fluids on mortality in patients with sepsis found that BCs or albumin had more benefits on mortality compared with other fluids. The septic subgroup in our study involving more direct and indirect comparisons confirmed these findings, and the SUCRAs value was used to sort the merits of the liquid. One meta-analysis ${ }^{2}$ that evaluated the association of HES use with mortality and AKI found that HES may increase the risk of mortality and AKI compared with other resuscitation solutions. However, the control group of this study contains various crystalloid solutions, which may bring in heterogeneity. Therefore, we adopted this NMA approach to reduce the heterogeneity, and the results showed that the HES may not be able to directly increase the risk of mortality. In addition, we found that the use of H-HES, rather than L-HES, was associated with an increased incidence of AKI and risk of receiving RRT. The molecular weight of HES should be considered in clinical use for acute volume resuscitation. Despite the fact that some patients undergoing non-trauma surgery where the purpose of fluid therapy is volume maintenance rather than fluid resuscitation, a previous meta-analysis ${ }^{70}$ including 59 RCTs consisting of 16,889 patients comparing the colloids with crystalloids in critically ill, trauma and surgical patients also found that colloid administration was not beneficial for mortality but did increase the risk of developing AKI requiring RRT.

Fluid management in critically ill patients has come under the spotlight in recent years. ${ }^{71}$ Fluid administration 
with various drug types, the formulation, the timing, and the dose can directly impact the outcomes of patients. ${ }^{72,73}$ Therefore, it is a clinical imperative to know their therapeutic and toxic windows to reach the optimal dose, as well as clinical decisions on type of fluid based on their side effect profile and risks and benefits. ${ }^{74}$

Normal saline is still the mostly used crystalloid all over the world although it causes hyperchloremic acidosis, which is known to impair renal function and predispose to infections. ${ }^{75,76}$ Contrarily, our analysis indicated that the use of H-HES was associated with an increased incidence of AKI and risk of receiving RRT. Whether the chloride-rich solutions will cause AKI is still controversial, and more trials with high qualities are needed to confirm these findings.

Fluid overload frequently occurs in critically ill patients. Early recognition and assessment of this issue in critically ill patients requires an accurate documentation of intakes and outputs. ${ }^{77}$ Among critically ill patients, exposure to positive or negative fluid balance was associated with higher 1-year mortality compared with euvolemic state. ${ }^{78}$ However, the most commonly used static parameters (such as central venous pressure [CVP] or pulmonary artery occlusion pressure $[\mathrm{PAOP}]$ ) cannot predict volume responsiveness, ${ }^{69}$ and echocardiography was recommended to predict and measure fluid responsiveness. ${ }^{79}$ Among the included studies, the patients may actually have positive and negative fluid balance, and this may influence the mortality or AKI incidence, which may be more prominent in choosing fluid types on patients. Therefore, when a patient needs fluid resuscitation, clinicians should not only consider the fluid type but also need to evaluate the fluid responsiveness with dynamic parameters (such as echocardiography).

\section{Limitations}

There are several limitations in this meta-analysis. First, although all included studies focused on fluid for resuscitation, protocols for fluid resuscitation were somewhat heterogeneous, with the varying amounts and durations of the fluid intervention. Second, we pooled trials from distinct patient populations (all of which were considered to be seriously ill requiring acute volume resuscitation), which may significantly increase the between-trial heterogeneity. Third, in some direct and indirect comparisons, only a small number of studies were included resulting in low confidence in estimates for many key analyses. Fourth, the actual sample size for specific comparisons was small, and no subgroup analyses could be performed to investigate potential sources of heterogeneity, which may also limit the strength of this study. Finally, articles written in language other than English were excluded, which may limit the representativeness of the findings.

\section{Conclusion}

$\mathrm{BCs}$, especially the Plasma-Lyte, are presumably the best choice for most critically ill patients who need fluid resuscitation. Meanwhile, the use of H-HES was associated with an increased incidence of AKI and risk of receiving RRT. When a patient needs fluid resuscitation, the amount, duration, and type of fluids should be carefully tailored, and the fluid responsiveness should be also evaluated by dynamic assessment methods.

\section{Acknowledgment}

This research received no specific grant from any funding agency in the public, commercial, or not-for-profit sectors.

\section{Disclosure}

The authors report no conflicts of interest in this work.

\section{References}

1. Rochwerg B, Alhazzani W, Sindi A, et al. Fluid resuscitation in sepsis: a systematic review and network meta-analysis. Ann Intern Med. 2014;161(5):347-355.

2. Zarychanski R, Abou-Setta AM, Turgeon AF, et al. Association of hydroxyethyl starch administration with mortality and acute kidney injury in critically ill patients requiring volume resuscitation: a systematic review and meta-analysis. JAMA. 2013;309(7):678-688.

3. Perel P, Roberts I, Ker K. Colloids versus crystalloids for fluid resuscitation in critically ill patients. Cochrane Database Syst Rev. 2013;2: CD000567.

4. Young P. Saline Is the Solution for Crystalloid Resuscitation. Crit Care Med. 2016;44(8):1538-1540.

5. Semler MW, Rice TW. Saline Is Not the First Choice for Crystalloid Resuscitation Fluids. Crit Care Med. 2016;44(8):1541-1544.

6. Myburgh JA, Mythen MG. Resuscitation fluids. N Engl J Med. 2013; 369(13):1243-1251.

7. American Thoracic S, American Thoracic Society. Evidence-based colloid use in the critically ill: American Thoracic Society Consensus Statement. Am J Respir Crit Care Med. 2004;170(11):1247-1259.

8. Krajewski ML, Raghunathan K, Paluszkiewicz SM, Schermer CR, Shaw AD. Meta-analysis of high- versus low-chloride content in perioperative and critical care fluid resuscitation. Br J Surg. 2015;102(1): 24-36.

9. Young P, Bailey M, Beasley R, et al. Effect of a Buffered Crystalloid Solution vs Saline on Acute Kidney Injury Among Patients in the Intensive Care Unit: The SPLIT Randomized Clinical Trial. JAMA. 2015; 314(16):1701-1710.

10. Verma B, Luethi N, Cioccari L, et al. A multicentre randomised controlled pilot study of fluid resuscitation with saline or Plasma-Lyte 148 in critically ill patients. Crit Care Resusc. 2016;18(3):205-212.

11. Semler MW, Wanderer JP, Ehrenfeld JM, et al. Balanced Crystalloids versus Saline in the Intensive Care Unit. The SALT Randomized Trial. Am J Respir Crit Care Med. 2017;195(10):1362-1372.

12. Semler MW, Self WH, Wanderer JP, et al. Balanced Crystalloids versus Saline in Critically Ill Adults. N Engl J Med. 2018;378(9):829-839. 
13. Hutton B, Salanti G, Caldwell DM, et al. The PRISMA extension statement for reporting of systematic reviews incorporating network meta-analyses of health care interventions: checklist and explanations. Ann Intern Med. 2015;162(11):777-784.

14. Miller DR. Update to readers and authors on ethical and scientific misconduct: retraction of the "Boldt articles". Can J Anaesth. 2011; 58779(9):777779-777781.

15. Reilly C. Retraction. Notice of formal retraction of articles by Dr Joachim Boldt. Br J Anaesth. 2011;107(1):116-117.

16. Higgins JP, Altman DG, Gøtzsche PC, et al. The Cochrane Collaboration's tool for assessing risk of bias in randomised trials. BMJ. 2011; 343:d5928.

17. Liu C, Mao Z, Yang M, et al. Efficacy and safety of daptomycin for skin and soft tissue infections: a systematic review with trial sequential analysis. Ther Clin Risk Manag. 2016;12:1455-1466.

18. Puhan MA, Schünemann HJ, Murad MH, et al. A GRADE Working Group approach for rating the quality of treatment effect estimates from network meta-analysis. BMJ. 2014;349:g5630.

19. Rochwerg B, Włudarczyk A, Szczeklik W, et al. Fluid resuscitation in severe sepsis and septic shock: systematic description of fluids used in randomized trials. Pol Arch Med Wewn. 2013;123(11):603-608.

20. Brown S, Hutton B, Clifford T, et al. A Microsoft-Excel-based tool for running and critically appraising network meta-analyses - an overview and application of NetMetaXL. Syst Rev. 2014;3:110.

21. Higgins JP, Thompson SG, Deeks JJ, Altman DG. Measuring inconsistency in meta-analyses. BMJ. 2003;327(7414):557-560.

22. Cipriani A, Higgins JP, Geddes JR, Salanti G. Conceptual and technical challenges in network meta-analysis. Ann Intern Med. 2013;159(2): $130-137$.

23. Salanti G, Ades AE, Ioannidis JP. Graphical methods and numerical summaries for presenting results from multiple-treatment meta-analysis: an overview and tutorial. J Clin Epidemiol. 2011;64(2):163-171.

24. Shah DM, Browner BD, Dutton RE, Newell JC, Powers SR. Cardiac output and pulmonary wedge pressure. Use for evaluation of fluid replacement in trauma patients. Arch Surg. 1977;112(10):1161-1168.

25. Jelenko C. Fluid therapy and the HALFD method. J Trauma. 1979; 19(11 Suppl):866-867.

26. Goodwin CW, Dorethy J, Lam V, Pruitt BA. Randomized trial of efficacy of crystalloid and colloid resuscitation on hemodynamic response and lung water following thermal injury. Ann Surg. 1983;197(5): 520-531.

27. Modig J. Advantages of dextran 70 over Ringer acetate solution in shock treatment and in prevention of adult respiratory distress syndrome. A randomized study in man after traumatic-haemorrhagic shock. Resuscitation. 1983;10(4):219-226.

28. Rackow EC, Falk JL, Fein IA, et al. Fluid resuscitation in circulatory shock: a comparison of the cardiorespiratory effects of albumin, hetastarch, and saline solutions in patients with hypovolemic and septic shock. Crit Care Med. 1983;11(11):839-850.

29. Rackow EC, Mecher C, Astiz ME, Griffel M, Falk JL, Weil MH. Effects of pentastarch and albumin infusion on cardiorespiratory function and coagulation in patients with severe sepsis and systemic hypoperfusion. Crit Care Med. 1989;17(5):394-398.

30. Vassar MJ, Perry CA, Holcroft JW. Analysis of potential risks associated with $7.5 \%$ sodium chloride resuscitation of traumatic shock. Arch Surg. 1990;125(10):1309-1315.

31. Vassar MJ, Perry CA, Gannaway WL, Holcroft JW. 7.5\% sodium chloride/dextran for resuscitation of trauma patients undergoing helicopter transport. Arch Surg. 1991;126(9):1065-1072.

32. Younes RN, Aun F, Accioly CQ, Casale LP, Szajnbok I, Birolini D. Hypertonic solutions in the treatment of hypovolemic shock: a prospective, randomized study in patients admitted to the emergency room. Surgery. 1992;111(4):380-385.

33. Nagy KK, Davis J, Duda J, Fildes J, Roberts R, Barrett J. A comparison of pentastarch and lactated Ringer's solution in the resuscitation of patients with hemorrhagic shock. Circ Shock. 1993;40(4):289-294.
34. Vassar MJ, Fischer RP, O’Brien PE, et al. A multicenter trial for resuscitation of injured patients with $7.5 \%$ sodium chloride. The effect of added dextran 70. The Multicenter Group for the Study of Hypertonic Saline in Trauma Patients. Arch Surg. 1993;128(9):1003-1011; discussion 1011-1003.

35. Vassar MJ, Perry CA, Holcroft JW. Prehospital resuscitation of hypotensive trauma patients with $7.5 \% \mathrm{NaCl}$ versus $7.5 \% \mathrm{NaCl}$ with added dextran: a controlled trial. J Trauma. 1993;34(5):622-632; discussion 632-623.

36. Beards SC, Watt T, Edwards JD, Nightingale P, Farragher EB. Comparison of the hemodynamic and oxygen transport responses to modified fluid gelatin and hetastarch in critically ill patients: a prospective, randomized trial. Crit Care Med. 1994;22(4):600-605.

37. Evans PA, Garnett M, Boffard K, Kirkman E, Jacobson BF. Evaluation of the effect of colloid (Haemaccel) on the bleeding time in the trauma patient. J R Soc Med. 1996;89(2):101P-104P.

38. Younes RN, Aun F, Ching CT, et al. Prognostic factors to predict outcome following the administration of hypertonic/hyperoncotic solution in hypovolemic patients. Shock. 1997;7(2):79-83.

39. Younes RN, Yin KC, Amino CJ, Itinoshe M, Rocha E, Silva M, Birolini D. Use of pentastarch solution in the treatment of patients with hemorrhagic hypovolemia: randomized phase II study in the emergency room. World J Surg. 1998;22(1):2-5.

40. Asfar P, Kerkeni N, Labadie F, Gouëllo JP, Brenet O, Alquier P. Assessment of hemodynamic and gastric mucosal acidosis with modified fluid versus $6 \%$ hydroxyethyl starch: a prospective, randomized study. Intensive Care Med. 2000;26(9):1282-1287.

41. Schortgen F, Lacherade JC, Bruneel F, et al. Effects of hydroxyethylstarch and gelatin on renal function in severe sepsis: a multicentre randomised study. Lancet. 2001;357(9260):911-916.

42. Wu JJ, Huang MS, Tang GJ, et al. Hemodynamic response of modified fluid gelatin compared with lactated ringer's solution for volume expansion in emergency resuscitation of hypovolemic shock patients: preliminary report of a prospective, randomized trial. World J Surg. 2001;25(5): 598-602.

43. Oliveira RP, Weingartner R, Ribas EO, Moraes RS, Friedman G. Acute haemodynamic effects of a hypertonic saline/dextran solution in stable patients with severe sepsis. Intensive Care Med. 2002;28(11): 1574-1581.

44. Alpar EK, Killampalli VV. Effects of hypertonic dextran in hypovolaemic shock: a prospective clinical trial. Injury. 2004;35(5):500-506.

45. Finfer S, Bellomo R, Boyce N, et al. A comparison of albumin and saline for fluid resuscitation in the intensive care unit. $N$ Engl J Med. 2004; 350(22):2247-2256.

46. Molnár Z, Mikor A, Leiner T, Szakmány T. Fluid resuscitation with colloids of different molecular weight in septic shock. Intensive Care Med. 2004;30(7):1356-1360.

47. Veneman TF, Oude Nijhuis J, Woittiez AJ. Human albumin and starch administration in critically ill patients: a prospective randomized clinical trial. Wien Klin Wochenschr. 2004;116(9-10):305-309.

48. Rizoli SB, Rhind SG, Shek PN, et al. The immunomodulatory effects of hypertonic saline resuscitation in patients sustaining traumatic hemorrhagic shock: a randomized, controlled, double-blinded trial. Ann Surg. 2006;243(1):47-57.

49. Brunkhorst FM, Engel C, Bloos F, et al. Intensive insulin therapy and pentastarch resuscitation in severe sepsis. $N$ Engl J Med. 2008; 358(2):125-139.

50. Bulger EM, Jurkovich GJ, Nathens AB, et al. Hypertonic resuscitation of hypovolemic shock after blunt trauma: a randomized controlled trial. Arch Surg. 2008;143(2):139-148; discussion 149.

51. Fang ZX, Li YF, Zhou XQ, et al. Effects of resuscitation with crystalloid fluids on cardiac function in patients with severe sepsis. BMC Infect Dis. 2008;8:50.

52. Mcintyre LA, Fergusson D, Cook DJ, et al. Fluid resuscitation in the management of early septic shock (FINESS): a randomized controlled feasibility trial. Can J Anaesth. 2008;55(12):819-826. 
53. Dolecek M, Svoboda P, Kantorová I, et al. Therapeutic influence of $20 \%$ albumin versus $6 \%$ hydroxyethylstarch on extravascular lung water in septic patients: a randomized controlled trial. Hepatogastroenterology. 2009;56(96):1622-1628.

54. van der Heijden M, Verheij J, van Nieuw Amerongen GP, Groeneveld AB. Crystalloid or colloid fluid loading and pulmonary permeability, edema, and injury in septic and nonseptic critically ill patients with hypovolemia. Crit Care Med. 2009;37(4):1275-1281.

55. Dubin A, Pozo MO, Casabella CA, et al. Comparison of $6 \%$ hydroxyethyl starch 130/0.4 and saline solution for resuscitation of the microcirculation during the early goal-directed therapy of septic patients. J Crit Care. 2010;25659(4):659.e1-65659.e1.

56. Gondos T, Marjanek Z, Ulakcsai Z, et al. Short-term effectiveness of different volume replacement therapies in postoperative hypovolaemic patients. Eur J Anaesthesiol. 2010;27(9):794-800.

57. Inal MT, Memiş D, Karamanlioglu B, Sut N. Effects of polygeline and hydroxyethyl starch solutions on liver functions assessed with LIMON in hypovolemic patients. J Crit Care. 2010;25(2):361.e1-e5.

58. Vlachou E, Gosling P, Moiemen NS. Hydroxyethylstarch supplementation in burn resuscitation - a prospective randomised controlled trial. Burns. 2010;36(7):984-991.

59. Bulger EM, May S, Kerby JD, et al. Out-of-hospital hypertonic resuscitation after traumatic hypovolemic shock: a randomized, placebo controlled trial. Ann Surg. 2011;253(3):431-441.

60. du XJ, Hu WM, Xia Q, Xj D, Wm H, et al. Hydroxyethyl starch resuscitation reduces the risk of intra-abdominal hypertension in severe acute pancreatitis. Pancreas. 2011;40(8):1220-1225.

61. James MF, Michell WL, Joubert IA, Nicol AJ, Navsaria PH, Gillespie RS. Resuscitation with hydroxyethyl starch improves renal function and lactate clearance in penetrating trauma in a randomized controlled study: the FIRST trial (Fluids in Resuscitation of Severe Trauma. Br J Anaesth. 2011;107(5):693-702.

62. Wu BU, Hwang JQ, Gardner TH, et al. Lactated Ringer's solution reduces systemic inflammation compared with saline in patients with acute pancreatitis. Clin Gastroenterol Hepatol. 2011;9717(8):710e711.

63. Guidet B, Martinet O, Boulain T, et al. Assessment of hemodynamic efficacy and safety of $6 \%$ hydroxyethylstarch $130 / 0.4$ vs $0.9 \% \mathrm{NaCl}$ fluid replacement in patients with severe sepsis: the CRYSTMAS study. Crit Care. 2012;16(3):R94.

64. Myburgh JA, Finfer S, Bellomo R, et al. Hydroxyethyl starch or saline for fluid resuscitation in intensive care. N Engl J Med. 2012;367(20): 1901-1911.

65. Perner A, Haase N, Guttormsen AB, et al. Hydroxyethyl starch 130/0.42 versus Ringer's acetate in severe sepsis. N Engl J Med. 2012;367(2) 124-134.
66. Annane D, Siami S, Jaber S, et al. Effects of fluid resuscitation with colloids vs crystalloids on mortality in critically ill patients presenting with hypovolemic shock: the CRISTAL randomized trial. JAMA. 2013;310(17):1809-1817.

67. Béchir M, Puhan MA, Fasshauer M, Schuepbach RA, Stocker R, Neff TA. Early fluid resuscitation with hydroxyethyl starch 130/0.4 $(6 \%)$ in severe burn injury: a randomized, controlled, double-blind clinical trial. Crit Care. 2013;17(6):R299.

68. Young JB, Utter GH, Schermer CR, et al. Saline versus Plasma-Lyte A in initial resuscitation of trauma patients: a randomized trial. Ann Surg. 2014;259(2):255-262

69. Schindler AW, Marx G. Evidence-based fluid management in the ICU. Curr Opin Anaesthesiol. 2016;29(2):158-165.

70. Qureshi SH, Rizvi SI, Patel NN, Murphy GJ. Meta-analysis of colloids versus crystalloids in critically ill, trauma and surgical patients. $\mathrm{Br} J$ Surg. 2016;103(1):14-26.

71. Hjortrup PB, Delaney A. Fluid management in the ICU: has the tide turned? Intensive Care Med. 2017;43(2):237-239.

72. Kalil AC, Kellum JA. Is Early Goal-Directed Therapy Harmful to Patients With Sepsis and High Disease Severity? Crit Care Med. 2017; 45(8):1265-1267.

73. Mcguire MD, Heung M. Fluid as a Drug: Balancing Resuscitation and Fluid Overload in the Intensive Care Setting. Adv Chronic Kidney Dis. 2016;23(3):152-159.

74. Frazee E, Kashani K. Fluid Management for Critically Ill Patients: A Review of the Current State of Fluid Therapy in the Intensive Care Unit. Kidney Dis. 2016;2(2):64-71.

75. Roquilly A, Loutrel O, Cinotti R, et al. Balanced versus chloride-rich solutions for fluid resuscitation in brain-injured patients: a randomised double-blind pilot study. Crit Care. 2013;17(2):R77.

76. Yunos NM, Bellomo R, Hegarty C, Story D, Ho L, Bailey M. Association between a chloride-liberal vs chloride-restrictive intravenous fluid administration strategy and kidney injury in critically ill adults. JAMA. 2012;308(15):1566-1572.

77. Claure-del Granado R, Mehta RL. Fluid overload in the ICU: evaluation and management. BMC Nephrol. 2016;17(1):109.

78. Balakumar V, Murugan R, Sileanu FE, Palevsky P, Clermont G, Kellum JA. Both Positive and Negative Fluid Balance May Be Associated With Reduced Long-Term Survival in the Critically Ill. Crit Care Med. 2017;45(8):e749-e757.

79. Miller A, Mandeville J. Predicting and measuring fluid responsiveness with echocardiography. Echo Res Pract. 2016;3(2):G1-G12.
Therapeutics and Clinical Risk Management

\section{Publish your work in this journal}

Therapeutics and Clinical Risk Management is an international, peerreviewed journal of clinical therapeutics and risk management, focusing on concise rapid reporting of clinical studies in all therapeutic areas outcomes, safety, and programs for the effective, safe, and sustained use of medicines. This journal is indexed on PubMed Central, CAS,

\section{Dovepress}

EMBase, Scopus and the Elsevier Bibliographic databases. The manuscript management system is completely online and includes a very quick and fair peer-review system, which is all easy to use. Visit http://www.dovepress.com/testimonials.php to read real quotes from published authors. 